
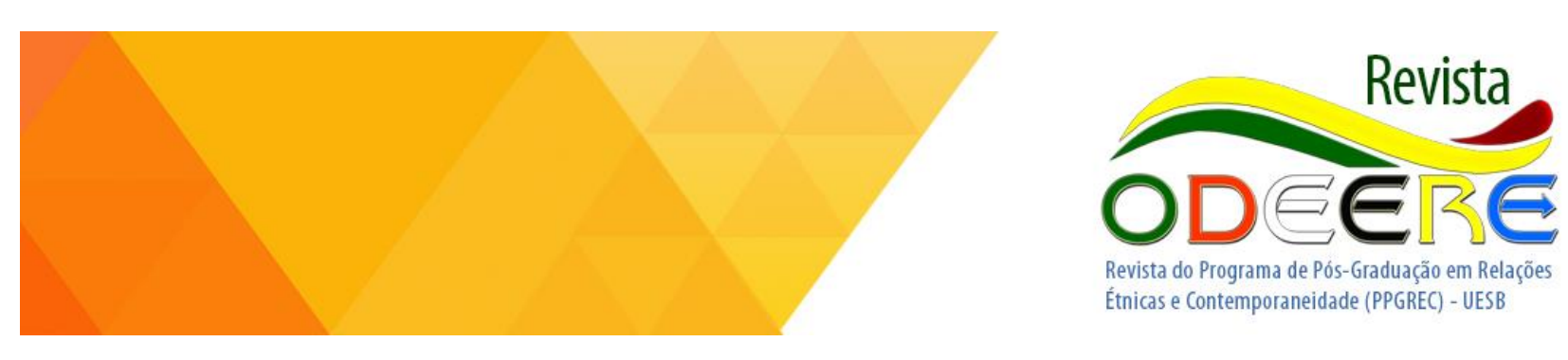

\title{
A adocicação do
} saci na cultura brasileira,

Ou

\section{O saci: oralidade, escrita, cultura de massa}

\author{
Jose Carlos Sebe Bom Meihy \\ Universidade do Grande Rio \\ (UNIGRARIO) \\ Universidade de São Paulo (USP) \\ jcarlosbm@hotmail.com
}

\begin{abstract}
Resumo:
Pensando a figura "folclórica" do Saci, a proposta deste texto visou dar forma a tantas ideias soltas, hipóteses formuladas ao longo de anos de suposições sobre a dinâmica de nossa identidade, brasileira, filtrada pelo saber popular, expressa pela indústria cultural. Também buscou-se explicar as transformações do personagem, visto como produto manipulado assumido pelo exercício de transposição de tradições transmitidas oralmente, mas que foram apropriadas como oficiais por meio de longo processo de filtragem de narrativas escritas e ilustradas, e assim, transformadas em mercadorias hoje incorporadas no contexto nacional. Pesou ainda a consideração do sutil constructo da memória coletiva como atributo integrante da requalificação do novo perfil brasileiro, na era da globalização, colocando temas amplos acima de questões de: gênero, classe, credo e principalmente de condição social.
\end{abstract}

\section{Abstract:}

Thinking on the Saci's "folk" figure, this text aims to analyses many ideas, hypotheses formulated throughout years of assumptions about the dynamics of the "Brazilian identity", filtered by popular knowledge, expressed by the cultural industry. It was also sought to explain the transformations of the character, seen as a manipulated product assumed by the exercise of transposition of popular oral traditions, usually transmitted, 
appropriated by "cultural officers" throughout a long process of filtering narratives, and thus, transformed into goods, now incorporated in the national context. It is also weighed for consideration the subtle construct of a Brazilian collective memory as an integral attribute of the requalification of the new national profile in the globalization era, placing broad themes above questions of gender, class, race, and especially of social condition.

\section{Saci: do mato para a sociedade de consumo}

Tendo como fio condutor a meditação sobre o traquinas personagem Saci - hoje tão recriado e propagado em diferentes suportes -, partiu-se do questionamento que pretendia ferir a possibilidade explicativa das mutações dessa figura submetida à relação mudanças $\mathrm{X}$ resistências. A proposta foi se firmando na medida em que se desenrolava o pressuposto histórico que reconhecia, no passado, um Saci amedrontador - ente das florestas temíveis e inconquistáveis, dono de assovio tétrico e ensurdecedor -, até a formulação de um simpático personagem - menino maroto, gracioso, perfeitamente integrado no gosto nacional. Dizendo de outra forma, me perguntava sobre a coerência entre tais variações e o "jeito maleável" que, de regra, no remete à interpretação da cultura brasileira como: incruenta, sem violência ou preconceito, esvaziada de agressividades e, sobretudo, destituída de percepções de luta de classes. E logo se me apresentou a explicação dos mecanismos da indústria cultural que explica a mercadorização de manifestações tradicionais que viram objetos de consumo. Foi por essa via que fez sentido o dizer da dupla Mattelart: "a transformação do ato cultural em valor suprime sua função crítica e nele dissolve os traços de uma experiência autêntica. A produção industrial sela a degradação do papel filosóficoexistencial da cultura". ${ }^{1}$

Assim, retraçava a hipótese deste trabalho: o que teria acontecido com a reformulação do assustador ente lendário que um dia foi senhor das florestas? O que restou dele e o que foi produzido até que chegasse ao mercado de consumo como uma espécie de duende domesticado? Situando o tema Saci no espaço indefinido do popular, público e erudito, marcou-se um momento de fundação do assunto em nosso discurso crítico/historiográfico. Remete-se a 1917, ano que viu

\footnotetext{
${ }^{1}$ MATTELART, A MATTELART, História das teorias da comunicação. São Paulo: Loyola, 1999, p. 78.
} 
fecundado o modernismo brasileiro, dimensionado em plenitude em 1922 e seguintes ${ }^{2}$. Evocando um tempo em que Monteiro Lobato desancava Anita Malfatti pela exposição de pintura, que tinha nítida vocação vanguardista, mostra introdutória do modernismo, trazia também a consideração que, ao mesmo tempo, mostrava um Lobato que se investia do dever de registro de relatos do Saci como personagem presente na compilação que chamou inicialmente de "Mitologia Brasílica Inquérito sobre o Saci-Pererê" ${ }^{3}$. Publicado no ano seguinte sobre o título de "O Saci-pererê: resultado de um inquérito" - seu primeiro livro -, pela mão de Lobato estava dada a largada para a crítica geral que se confundia na redefinição da cultura nacional, notadamente no viés paulista, urbano-industrial, que, por fim, daria sentido ao programa de nacionalidade cultural, expresso a partir "Semana de Arte Moderna". De igual maneira, se reconhece naquele nascedouro a eterna bipolaridade do posicionamento de José Bento Monteiro Lobato. Entre golpeio ao modernismo na pintura e a exaltação do Saci atualizado no espaço da cultura popular urbana, floria a ambiguidade que sempre sombreou o criador do Jeca Tatu que, aliás, mais tarde o trocou pela corte a Mr Slang, ao modelo industrial e demais temas que, por fim, legaram nossa mitologia à "pedagogização" infantil. Daí o inequívoco divisor da obra de Monteiro Lobato entre escritos para crianças $X$ escritos para adultos.

Convém lembrar que o modernismo brasileiro pretendia refundar o caráter nacional baseado em alguns supostos convenientes à nova visão de brasilidade. Ao apregoar, por exemplo, a modernidade, revia-se os fundamentos da história nacional, detratando sobremaneira os portugueses e o catolicismo. Foi exatamente neste esquema que se abriu avenidas para a valorização da mitologia indígena e negra, espaços em que transitariam personagens "autênticos", nossos, como o Saci.

\section{Oralidade, escrita e mercadorização: o consumo do saci.}

A amplitude da proposta desenhava um rumo progressivo, sem limites. A temeridade no enfrentamento da questão se justificava pela largura dos aspectos que cruzam evocações tidas

\footnotetext{
${ }^{2}$ BATISTA, Marta Rossetti. Anita Malfatti no tempo e no espaço: biografia e obra. São Paulo: Editora 34 - EDUSP, 2006. CHIARELLI, Tadeu. Tropical, de Anita Malfatti: reorientando uma velha questão. São Paulo: Novos Estudos Cebrap, 2008, no80. REZENDE, Neide. A Semana de Arte Moderna. Coleção Princípios. São Paulo: Ática, 1993.

${ }^{3}$ Sobre o tema, veja-se o artigo de Marisa Lajolo, Saci or not Saci: that is the question, in Monteiro Lobato livro a livro: obra adulta, Marisa LAJOLO (org.), Editora UNESP, São Paulo, 2014, pp. 25 - 39.
} 
como subjetivas, detalhes escondidos em nossa memória coletiva sob a camada complexa da suposta modernização da cultura brasileira. Mas, bastou iniciar o processo de pesquisa para que o caminho se tornasse irreversível. Amarrando diferentes fios estavam os desafios propostos para um historiador que se aventura falar do trânsito cultural, de que gosta da costura entre literatura e história e da crítica a Monteiro Lobato em particular quando leva em conta expressões de linguagens da memória. Pronto, não tinha mais caminho de volta, o Saci já havia feito estragos na possibilidade de renúncia, e, dessa forma, estava metaforizado o redemoinho que me levaria para o fundo do rio onde, aliás, moradia o Saci.

Mas como dar o passo seguinte? Por evidente, li o que tinha ao alcance. Retomei, por exemplo, "Histórias de Tia Nastácia" e o "Saci" e voltei ao diálogo que mantenho com Marisa Lajolo, desde 1988, sobre o negro na literatura lobateana ${ }^{4}$. Visitei também contos, poemas, canções de vários autores que abordam o assunto, direta ou de maneira tangente. Revi comentários críticos e não desdenhei os debates recentes sobre o racismo na produção literária, folclórica e histórica ${ }^{5}$. Foi difícil escapar dessa contenda que, pela mitologia nacional inscreve, com sedução, o tema Saci. Respeitando os ensinamentos de Florestan Fernandes sobre questões folclóricas, no encalço de avanços, procurei alinhavar num mesmo pano informações e análises ${ }^{6}$.

A continuidade da proposta me levou a uma vertiginosa viagem do passado para o presente, mas também do presente para o passado, sempre buscando as possíveis raízes da figura do Saci e suas projeções na contemporaneidade. E foi assim que me vi no encalço de registros das primeiras manifestações, anotadas no século XIX. Preocupou-me também a incorporação, pela literatura, para, a partir, dela me abrir para as novas mídias como cinema, cancioneiro gravado, quadrinhos, filmes e principalmente séries de televisão. E logo ficava claro que existem duas raízes que explicam as recepções do mesmo personagem: uma destilada das repetições oralizadas, caipiras, garantidas com autenticidade pela repetição, e, outra, que passa pelo crivo da indústria cultural, filtrada pela escrita e pelas variações imagéticas da sociedade de massa. O mero enunciado dessa trajetória me sugeria algum caminho, ainda que tortuoso, cheio de atalhos. Foi quando juntei matéria variada, começando a pavimentar uma narrativa bricolada, tendo como

\footnotetext{
${ }^{4}$ Sobre o assunto ver o artigo A Figura do Negro em Monteiro Lobato, por Marisa LAJOLO. Disponível em: http://www.unicamp.br/iel/monteirolobato/outros/lobatonegros.pdf, acessado em 30/10/2016.

${ }^{5}$ Dentre tantos escritos sobre o tema vale destacar de DUARTE, Eduardo de Assis Literatura e afrodescendência no Brasil: antologia crítica. 4 volumes. Belo Horizonte: Editora UFMG. 2011.

${ }^{6}$ FERNANDES, Florestan, O folclore em questão. São Paulo, Hucitec. 1987.
} 
eixo definidor a inscrição desse personagem em linhagens bipartidas. E novamente, Lobato despontava como causador desse fracionamento.

Perguntava-me, então, se havia um Saci tradicional e outro moderno ou modernizado? E ficava clara a hegemonia das camadas letradas que fabricam um Saci novo, uma entidade algo exótica, ser esquisito sim, mas tolerável, presente construção de uma identidade nacional oficializada ${ }^{7}$. Com certeza não me restava acatar uma ideia linear, capaz de mostrar apenas uma imagem do Saci. Metamorfoseando o ente misterioso, procurei não deixar de lado seu perfil conhecido no presente, mas precisei ler em sua suposta trajetória algumas contradições que, por fim, levavam à ambígua divisão: campo X cidade. Não menos provocativa foi a suposição de uma mitologia oralizada, repetida por camponeses iletrados, e outra mercadorizada, de cidadãos do mundo industrial urbano. Foi nesse encalço, pensando no "velho" Saci que retracei uma possibilidade analítica que passa me desafiar: será que o Saci oralizado, o tal protetor das matas, não teria a ver com os negros quilombolas, fugitivos escravos que auto-retirados do sistema, assombrariam os brancos? A pergunta ficava no ar...

\section{A Construção do Saci Brasileiro.}

De onde teria vindo as lendas do Saci? Das três alternativas mais usuais - indígena, africana ou europeia - tive que prezar todas. Pensei de saída que, ante a impossibilidade de precisão, me era obrigatório apoiar, comodamente, no conceito de "metamorfose" 8 . Pensando na gravidade da leitura crítica sobre tal posicionamento, restou apelar para o cenário antropofágico que caracteriza a moderna percepção da cultura brasileira como um todo. Sim, é inegável que a imprecisão da origem de figuras como o Saci leva à formulação de um modelo hegemônico que se materializa na conceituação do que é nacional. Nesse contexto, reina a estratégia das negociações, ou da incorporação e da reversão de tudo que vem "de fora" compondo o perfil nacional, brasileiro. Em certa medida, isso explicaria o Lobato contraditório, senhor de afirmativas condizentes com o modernismo - no caso do folclore/tradições - e negações - segundo a

\footnotetext{
${ }^{7}$ Para tal pressuposição pesaram os argumentos expressados por Jessé SOUZA ao criticar Roberto DAMATTA na simplificação decorrente do "jeitinho brasileiro". Sobre o assunto leia-se A tolice da inteligência brasileiria: como o país se deixa manipular pela elite. Leya, São Paulo, 2015, pp. 69 - 88.

${ }^{8}$ Foram fundamentais as propostas indicadas por Gilles LIPOVESTSKY que, apoiado em Voltaire e Kant, desenhou o sentido das transformações liberais sob a égide midiática. Sobre o assunto leia-se Metamorfose da cultura liberal: ética, mídia e empresa. Editora Sulina, Porto Alegre, 2004.
}

Odeere: revista do programa de pós-graduação em Relações Étnicas e Contemporaneidade - UESB. ISSN 25254715, Ano 1, número 2, volume 1, Julho - Dezembro de 2016. 
percepção da estética apregoada pela norma dos intelectuais de 1922. Mas, como nem só de Lobato se nutrem os argumentos sobre o Saci, me vi na contingência de complementos.

A fim de dar contorno analítico para a construção do Saci como personagem nacional, parti do pressuposto de que hoje ele é figura palatável, aceito, principalmente fabricado para crianças, ainda que cá e lá se valha dele como referência "exaltativa" de certa brasileiridade nacionalista ${ }^{9}$. Fala-se, aliás, de uma dupla infantilização: do Saci adulto, negro raivoso, soberano dos matos, depois tornado menino arteiro, e nele personagem destinado às crianças. As duas faces dessa moeda negociam um longo processo de apresamento e construção do personagem, estabelecido segundo a imagem e semelhança da cultura que atesta o perfil brasileiro negociador. Outro elemento considerável nesta análise é o fato desse personagem caminhar progressivamente como tema pedagógico, lúdico, e, nesse processo, validado como estratégia ideológica, se confirmaria o princípio da antropofagia, pois a imagem que hoje temos do Saci é de uma figura transformada. Sem dúvida, o padrão dado pela Rede Globo de Televisão nas várias versões do programa "Sítio do pica pau amarelo" mostra um garoto, negrinho/mulato simpático, de uma só perna, capuz e calça vermelhos. O Saci de nossos dias, não é mais o maldoso ente que atormentava a todos, mas um cativante malandrinho que faz suas travessuras engraçadas ${ }^{10}$. De maneira sorrateira, em favor do "politicamente correto", foram aliviados o olhar ameaçador e retirado o "condenável" pito/cachimbo, não mais solta fumaça pelos olhos. Mas, no longo processo "metamorfoseador", isso é só mais um detalhe.

Talvez os mais convincentes argumentos demonstrativos do processo de infantilização do Saci e de seu endereço para uma cultura infantilizante sejam as leituras procedidas tanto por Maurício de Souza como por Ziraldo ${ }^{11}$. Por lógico tudo ocorreu em consonância com as séries patrocinadas pela televisão nos episódios do "Sítio". A importante sequência de histórias feitas

\footnotetext{
${ }^{9}$ Ainda que haja nítidas aproximações do "nosso" Saci com personagens mitológicos/populares de muitas culturas, há, entre nós, um esforço de definição da exclusividade desse ente.

${ }^{10}$ Entre as travessuras delegadas ao Saci, destacam-se o fato de rondar pessoas desavisadas, esconder brinquedos e apetrechos de casa, dar nó em crina de cavalos, misturar roupas, esconder objetos, espalhar sal e açúcar, apagar o fogo aceso e assombrar pessoas com estridente assobio.

${ }^{11}$ Em relação a Mauricio de Souza ver a extensa lista de pequenos filmes sobre o Saci in https://www.google.com.br/search?q=saci+mauricio+de+souza\&ie=utf-8\&oe=utf-8\&client=firefox-bab\&gfe $r d=c r \& e i=Q-8 Z W L 2 L O s$ M8AeC7KyoBg. Não menos expressiva a relação de Ziraldo in https://www.youtube.com/watch?v=6 qVbCJ96cw. De tal forma para Ziraldo foi importante a referência do Saci que ele criou a chamada "família Pererê", sobre o assunto veja-se: https://www.youtube.com/watch?v=6 qVbCJ96cw, acessado em 26/10/15.
} 
para crianças, no Brasil, se inaugurou em 1952, na TV Tupi. O programa ficou no ar por 11 anos se constituindo enorme sucesso. Em 1964, na abertura da ditadura militar, o programa infantil que contextualizava o Saci, ganhou versão da TV Cultura de São Paulo e, em 1967, na TV Bandeirantes. Ainda que com intervalos, de 1977 a 1986, a Rede Globo de Televisão produziu o "Sítio", com destaque para a presença do Saci. Estava então caracterizado o novo Saci, nascido para entreter, não mais para criar problemas. E a figura do negrinho domesticado estava fixada.

\section{A histórica tropicalização do saci.}

Mas, e outro Saci? Dando asas ao voo histórico afeito aos registros documentais, me permiti pensar no Saci como variante tropicalizado do diabo, antes formulado segundo os rigores europeus. Não há como deixar de aproximá-lo, em sua origem, dos entes satânicos, pois desde as cores usadas em suas representações como nas maldades inerentes ao seu papel, há sugestões de transferências $^{12}$. Contrastando com a versão daquele demo, pude pensar na gênese da "adocicação" do Saci que, entre nós não manteve, odores insuportáveis, perdeu o rabo e trocou o espeto pelo cachimbo e ao longo do tempo perdeu também o buraco das mãos por onde passavam brasas. As negociações, diga-se, seriam desdobradas progressivamente, até o completo controle do personagem, entre nós.

Talvez, essa prática de tradução das severidades metropolitanas, na colônia, explique também outra hipótese interessante, de aproximação entre as entidades maléficas europeias e a possibilidade da origem paraguaia do Saci. Há informações que prezam, desde os primeiros tempos de contato, a identificado do nosso Saci com Yasy Yateré, alguém que teria, no mínimo atitudes próximas, principalmente o zelo das matas e as tapeações com pessoas de fora" ${ }^{13}$. Nesse caso, desde o século XVIII, dada a dispersão dos Guarani rumo a diferentes espaços brasileiros, seria possível a difusão pelo Brasil. E há versões que contemplam detalhes regionais da adaptação

\footnotetext{
${ }^{12}$ Mesmo antes de ser nominado Saci, há referências interessantes que pouco têm sido prezadas em favor da construção o personagem apropriado pelo nosso folclore. Não deixa de ser significativa a referência a uma obra do início do século XVIII, atribuída da Antonio José da Silva, O Judeu, que contava de um personagem traquinas que tinha a mão furada, como mais tarde seria o Saci. Sobre o assunto leia-se SILVA, Antônio José. Obras do diabinho da mão furada. Org. João Gaspar Simões. Lisboa: Arcádia, 1973.

${ }^{13}$ Autores com Horácio Quiroga e outros exploram a fecundidade dessa lenda e suas apropriações pelos missionários do sul do Brasil. Sobre o assunto leia-se a relação proposta em http://www.buenastareas.com/materias/yaciyater\%C3\%A9/0, acessado em 20/10/2016.
}

Odeere: revista do programa de pós-graduação em Relações Étnicas e Contemporaneidade - UESB. ISSN 25254715, Ano 1, número 2, volume 1, Julho - Dezembro de 2016. 
do Saci $^{14}$. No nordeste brasileiro, por exemplo, acredita-se que suas manifestações decorrem da raiva de um moleque que perdeu a perna num jogo de capoeira ${ }^{15}$. No norte, é comum aproximá-lo da ave Matintaperera ave de pio estridente que, em 1973, foi incorporada na canção "águas de março". Diga-se, aliás, que o álbum intitulado Matita Perê, remete a uma tradição que diz de um pássaro noturno que vira gente durante o dia, assombrando os transeuntes perdidos na floresta. Uma referência indispensável remete a busca da origem da palavra Saci que, pode ter sido originada no termo tupi Sa + si o que não deixa de sugerir ligações com o matintape're.

O entendimento da transfiguração do Saci é condição afirmativa da adocicação ocorrida no personagem. E isso não acontece apenas na ficção. Também na "vida real" há transposições que vão além das várias denominações, assumidas Brasil afora: Saci-Cererê, Saci-Trique, Saçurá, Mati-taperê, Matiaperê, Matimpererê, Matintaperera, Capetinha da Mão Furada ${ }^{16}$. O que importa mesmo no momento é verificar que a meditação sobre o Saci, de folclórico, de coisa do povo, escapou também do campo literário ou sociológico. O longo e complexo processo de adocicação remete à transposição da oralidade folclórica para a cultura de massa. E é aí que atua a televisão, o rádio, o disco. A chamada cultura de massa tem feito muito em favor da determinação de um novo perfil do povo brasileiro. E aí atuam vários instrumentos combinados.

\section{Processos paralelos da adocicação do saci.}

A música, diga-se, foi importante instrumento nesse trajeto. Em 1912, por exemplo, VillaLobos compôs a marcha "Saci" como parte de peça inspirada em nosso folclore. Na mesma chave erudita Francisco Mignone também produziu uma peça com o mesmo nome, "Saci", feita especialmente para homenagear o personagem, em 1931. Também para piano Edmundo VillaniCortes compôs, em 1992 "Primeira folha do diário do saci", "Terceira folha do diário de um saci"

\footnotetext{
${ }^{14}$ QUEIROZ, Renato explora a apropriação do personagem entre nós no livro Um Mito bem Brasileiro: estudo antropológico sobre o Saci. São Paulo, Editora Polis, 1987.

${ }^{15}$ Sem dúvidas, o mais importante texto sobre os itinerários brasileiros do Saci se deve a CÂMARA CASCUDO, Luis da. Geografia dos Mitos Brasileiros. Rio de Janeiro: José Olympio, 1947.

${ }^{16}$ Aliás, o jornalista Mouzar Benedito diz que "E o Saci representa bem o brasileiro: é pobre (nem roupa tem), negro e perneta... e vive alegre, é brincalhão. Além disso, ele era índio na origem, virou negro e ganhou o gorrinho mágico dos europeus. É mesmo a síntese do brasileiro. É ícone do nosso imaginário. E o que seria da literatura sem o imaginário?" in https://blogdaboitempo.com.br/2011/11/29/o-saci-como-icone-da-identidade-nacional-na-literatura/ , acessado dia 28/10/2014.
} 
(para flauta) e "Sétima folha do diário de um saci" (para contrabaixo). O grande legado, contudo, se deu na passagem do erudito instrumental, para o popular, e, isso se inaugurou em 1909 com Chiquinha Gonzaga que gravou, com a dupla Os Geraldos, "Saci-Pererê". Em 1913, a polca "Saci" de J.B. Nascimento, foi gravada pelo Sexteto da Casa. Como toada, em 1918, Gastão Formenti cantou "Saci-Pererê", de autoria de Joubert de Carvalho. E daí para a frente várias canções se perfilaram em diferentes ritmos nacionais: marchas, sambas, baiões serestas -18 no total. Talvez alguns destaques ilustrem a popularidade e recepção do tema pelo público urbano que passava, gradativamente, a consumir discos: Zé Pagão \& Nhô Rosa gravaram "Saci-Pererê", de Ivani em 1949; Inhana fez enorme sucesso com o baião "Saci", de Antônio Bruno e Ernesto lanhaen, em 1956; a dupla Torrinha \& Canhotinho, fez "Saci-Pererê", em 1959; mas quem "estourou" mesmo foi Araci de Almeida com "Saci-Pererê", marcha de Henrique de Almeida e Rubi, cantada em 1960. Atravessando o tempo, em 196,1 apareceu uma novidade cantada por Demetrius o "Rock do Saci", de J. Marascalco e Richard Penniman. O limite dessa saga, contudo, se deu em 1972, com o Tom Jobim na "Águas de março", parte do álbum Matita Perê, lançado em 1973 e interpretado por Elis Regina. Mas a popularização da figura que se tornava mítica, não parou por aí. Grupos e interpretes populares passaram pelo tema, e, entre outros destacam-se o Secos \& Molhados, Falamansa, Cheiro de amor, bem como Kleiton e Kledir, Almôndegas que aliás, colocou a canção como tema da telenovela "Saramandaia".

A proposta analítica, visa mostrar que pela popularização - pela oralidade cantada - deuse a apropriação do Saci para crianças e nesse encalço nada mais foi eficiente do que a tomada do tema pela televisão. Imagem e movimento e música dimensionaram temas correlatos como Saci gravado composto por Guto Graça Mello. Mais tarde cantores reputados como Jorge Benjor e Carlinhos Brown seguiram os mesmos passos. E as variações se multiplicaram com Boca Livre, "Saci", (Paulo Jobim/Ronaldo Bastos, 1980); Ruy Maurity, "Sacirerê" (Maurity/Zé Jorge, 1984); Gilberto Gil, "Saci-Pererê" (Gil, 1980); Bia Bedran, "Quintal" (Bedran, 1992); Mônica Salmaso, "Saci" (Guinga/Paulo César Pinheiro, 1998); Gal Costa, "Grande Final" (Moraes Moreira, 2004); A Cor do Som, "Dança, Saci" (Mu Carvalho, 2006); Flávio Paiva, "A festa do Saci" (Paiva/Orlângelo Leal, 2007).

Pronto, está dada a largada para se pensar na dinâmica construção de um personagem que se popularizou no compasso da nacionalização da cultura brasileira. Por trabalhar com 
memória coletiva, não dá para definir autoria ou sequer os passos da manipulação do processo. Mas, sem dúvida, é possível problematizar uma aventura que consagra as estripulias de um personagem tão inquieto como a identidade nacional, brasileira.

\section{Bibliografia:}

\section{Sites}

https://www.google.com.br/search?q=saci+mauricio+de+souza\&ie=utf-8\&oe=utf8\&client=firefox-b-ab\&gfe $r d=c r \& e i=Q-8 Z W L 2 L O s$ M8AeC7KyoBg. https://www.youtube.com/watch?v=6 qVbCJ96cw.

https://www.youtube.com/watch?v=6 qVbCJ96cw

http://www.buenastareas.com/materias/yaciyater\%C3\%A9/0

https://blogdaboitempo.com.br/2011/11/29/o-saci-como-icone-da-identidade-nacional-naliteratura/

http://www.unicamp.br/iel/monteirolobato/outros/lobatonegros.pdf

\section{Artigos e Livros}

BATISTA, Marta Rossetti. Anita Malfatti no tempo e no espaço: biografia e obra. São Paulo: Editora 34 - EDUSP, 2006.

CÂMARA CASCUDO, Luis da. Geografia dos Mitos Brasileiros. Rio de Janeiro: José Olympio, 1947.

CHIARELLI, Tadeu. Tropical, de Anita Malfatti: reorientando uma velha questão. São Paulo: Novos Estudos Cebrap, 2008, n요.

DUARTE, Eduardo de Assis. Literatura e afrodescendência no Brasil: antologia crítica. 4 volumes. Belo Horizonte: Editora UFMG. 2011.

FERNANDES, Florestan. O folclore em questão. São Paulo, Hucitec. 1987.

LAJOLO, Marisa (org.) Saci or not Saci: that is the question, in Monteiro Lobato livro a livro: obra adulta Editora UNESP, São Paulo, 2014.

LIPOVESTSKY, Gilles. Metamorfose da cultura liberal: ética, mídia e empresa. Editora Sulina, Porto Alegre, 2004.

MATTELART, A MATTELART. História das teorias da comunicação. São Paulo: Loyola, 1999. 
REZENDE, Neide. A Semana de Arte Moderna. Coleção Princípios. São Paulo: Ática, 1993.

QUEIROZ, Renato Um Mito bem Brasileiro: estudo antropológico sobre o Saci. São Paulo, Editora Polis, 1987.

SILVA, Antônio José. Obras do diabinho da mão furada. Org. João Gaspar Simões. Lisboa: Arcádia, 1973.

SOUZA, Jessé. A tolice da inteligência brasileira: como o país se deixa manipular pela elite. Leya, São Paulo, 2015.

Jose Carlos Sebe Bom Meihy: atualmente é professor do Programa de Pós graduação Interdisciplinar em Letras e Ciências Humanas, da Universidade do Grande Rio. É professor aposentado do Departamento de História da Universidade de São Paulo, onde obteve os títulos de doutor e livre-docente e titular respectivamente em 1975, 1981 e 1992. Ocupou, na USP, a cadeira de História Ibérica e ministrou diversas disciplinas correlatas, tais como ?Guerra Civil Espanhola? e ?Modernidade e Conquistas Ultramarinas Portuguesas?. Atuou como professor/pesquisador visitante em diversas universidades fora do Brasil, como Standford, Miami e Columbia nos Estados Unidos e na África na Universidade Agostinho Neto, em Angola. Pioneiro nos estudos de história oral no Brasil, foi um dos idealizadores da Associação Brasileira e História Oral (ABHO), tendo sido diretor regional Sudeste nos biênios de 1994-1996 e 1996-1998. Atualmente é coordenador do Núcleo de Estudos em História Oral da USP (NEHO-USP). Tem experiência na área de História, com ênfase em História Oral, História Moderna e Contemporânea, atuando principalmente nos seguintes temas: história oral, teoria e metodologia, cultura brasileira, guerra civil espanhola, literatura e movimentos migratórios. Desenvolve pesquisas sobre processos migratórios em geral, com ênfase no tema dos deslocamentos de brasileiros fora do Brasil. Na Universidade do Grande Rio pesquisa grupos migratórios para a Baixada Fluminense, analisando aspectos subjetivos da negociação de identidades regionais.

Artigo recebido para publicação em: Outubro de 2016.

Artigo aprovado para publicação em: Dezembro de 2016. 